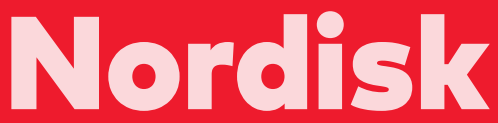
stotistik 2018

MID Nordiska ministerrådet 


\section{Nordisk statistik 2018}

Red: Ulla Agerskov och Silva Mertsola, Nordiska ministerådet

ANP 2018:818

ISBN 978-92-893-5823-1 (PRINT)

ISBN 978-92-893-5824-8 (PDF)

ISBN 978-92-893-5825-5 (EPUB)

http://dx.doi.org/10.6027/ANP2018-818

(C) Nordiska ministerrådet 2018

Layout: Mette Agger Tang

Tryck: Rosendahls

Printed in Denmark

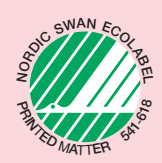

\section{Det nordiska samarbetet}

Det nordiska samarbetet är ett av världens mest omfattande regionala samarbeten. Det omfattar Danmark, Finland, Island, Norge och Sverige samt Färöarna, Grönland och Åland.

Det nordiska samarbetet är politiskt, ekonomiskt och kulturellt förankrat och en viktig del av europeiskt och internationellt samarbete. Den nordiska gemenskapen arbetar för ett starkt Norden i ett starkt Europa.

Det nordiska samarbetet vill styrka nordiska och regionala intressen och värderingar i en global omvärld. Gemensamma värderingar länderna emellan bidrar till att stärka Nordens ställning som en av världens mest innovativa och konkurrenskraftiga regioner. 
Nordisk

statistik

2018 
Graferna och tabellerna baserar sig på tal från den nordiska statistikdatabasen som består av ett brett urval jämförbar nordisk statistik samlad från bland annat nationella statistikbyråer och internationella organisationer.

Du hittar den nordiska statistikdatabasen här: norden.org/statistik 


\section{Förord}

Denna fickversion av Nordisk statistik 2018 ger dig en inblick i den statistik som tecknar konturerna av våra nordiska samhällen.

De nordiska länderna är små var för sig, men tillsammans är de betydelsefulla. För att sätta Norden i ett internationellt perspektiv, har vi kompletterat de nationella talen med internationella tal. Visste du att den nordiska varuexporten är lika stor som två tredjedelar av Japans samlade export? Eller att Norden är geografiskt större än hela Indien och därmed sjunde störst i världen?

Fickbokens teman avspeglar de tvärgående ämnena inom det nordiska samarbetet - t.ex. barn och unga, jämställdhet och hållbarhet. Även om de nordiska länderna är väldigt lika, så finns det stora skillnader mellan länderna.

Om du vill fördjupa dig ytterligare i nordisk statistik kan du besöka www.norden.org. Där hittar du den nordiska statistikdatabasen och flera siffror som öppnar för många intressanta analyser.

Trevlig läsning! 
Danmark

Färöarna

Grönland

Finland

Åland

Island

Norge

Sverige

Norden

Europeiska unionen
DK

FO

GL

$\mathrm{FI}$

AX

IS

NO

SE

NR

EU 


\section{Innehåll / teman}

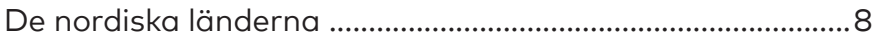

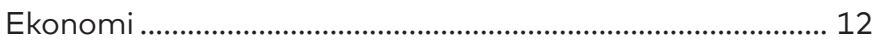

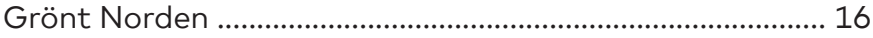

Kön, näringsliv och arbete ...................................................... 20

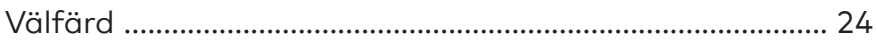

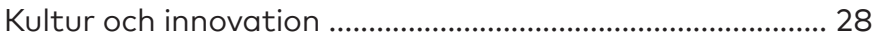

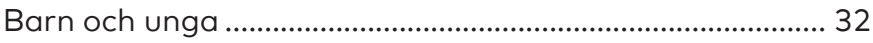




\section{De nordiska länderna}

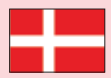

Danmark

Areal km²

42926

Befolkning

5781190

Statsskick/status

Konstitutionell monarki

Statsöverhuvud

Huvudstad

Drottning Margrethe II

Köpenhamn

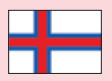

\section{Färöarna}

Areal km²

Befolkning

1396

Statsskick/status 50498

Statsöverhuvud

Huvudstad

Självstyre, del av kungariket Danmark Drottning Margrethe II

Torshamn



\section{Grönland}

Areal km²

Befolkning

2166086

Statsskick/status

Statsöverhuvud

Huvudstad

\section{7}

Självstyre, del av kungariket Danmark Drottning Margrethe II

Nuuk

\section{Sverige}

Areal km²

447435

Befolkning

10120242

Statsskick/status

Konstitutionell monarki

Statsöverhuvud

Huvudstad

Kung Carl XVI Gustav

Stockholm 


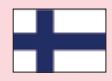

Finland

Areal km²

338430

Befolkning

5513130

Statsskick/status

Republik

Statsöverhuvud

Huvudstad

President Sauli Niinistö

Helsingfors



\section{Åland}

Areal $\mathrm{km}^{2}$

1583

Befolkning

29489

Statsskick/status

Självstyre, del av republiken Finland

Statsöverhuvud

Huvudstad

President Sauli Niinistö

Mariehamn

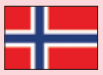

\section{Norge}

Areal $\mathrm{km}^{2}$

Befolkning

Statsskick/status

Statsöverhuvud

Huvudstad

\section{8}

5295619

Konstitutionell monarki

Kung Harald V

Oslo

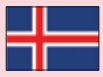

\section{Island}

Areal $\mathrm{km}^{2}$

Befolkning

Statsskick/status

Statsöverhuvud

Huvudstad

103492

348450

Republik

President Guðni Jóhannesson

Reykjavik 
Folkmängd

Miljoner (2017)

NORDEN

27 ก巾

EU

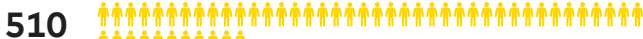

JAPAN

USA

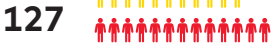

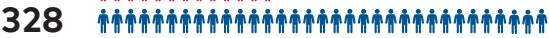

\section{Befolkningstäthet}

Invånare $/ \mathrm{km}^{2}$ (2017)

NORDEN 17



JAPAN 348

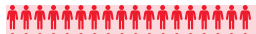

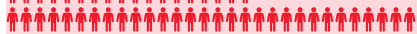

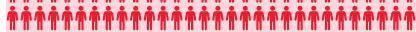



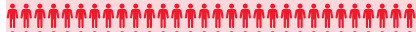

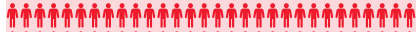

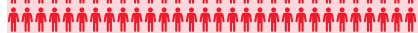

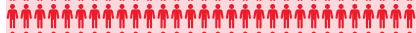

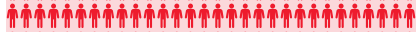

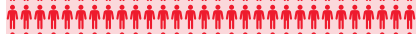



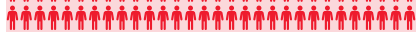

EU 118



USA 35

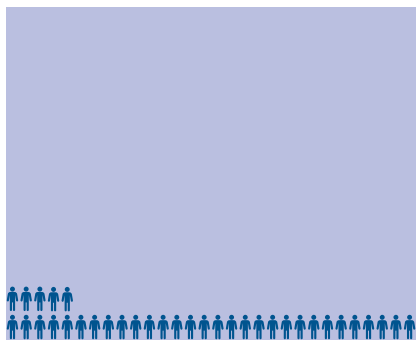


Total landareal

$1000 \mathrm{~km}^{2}$ (2017)

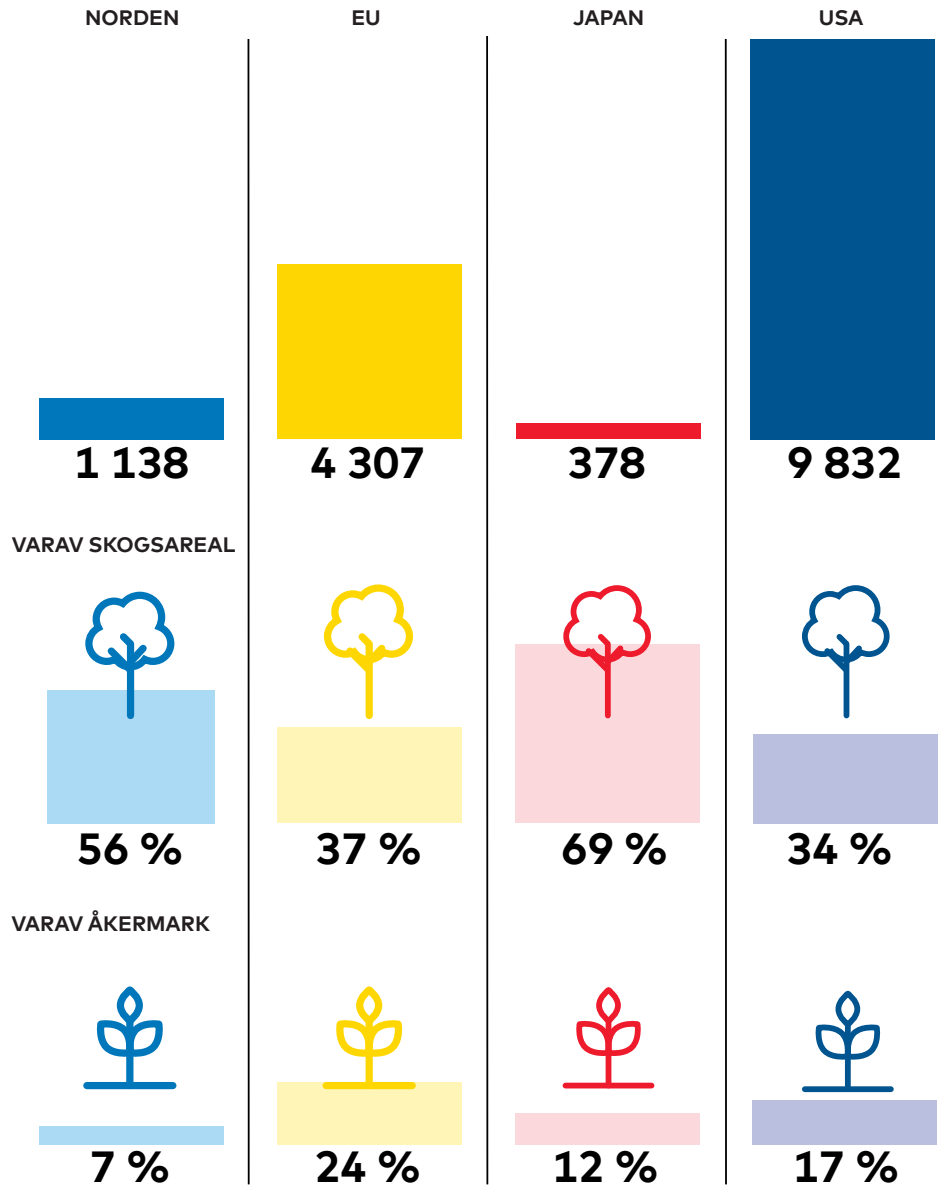




\section{Ekonomi}

\section{Arbetslöshet}

Procent 15-64 år (2017)

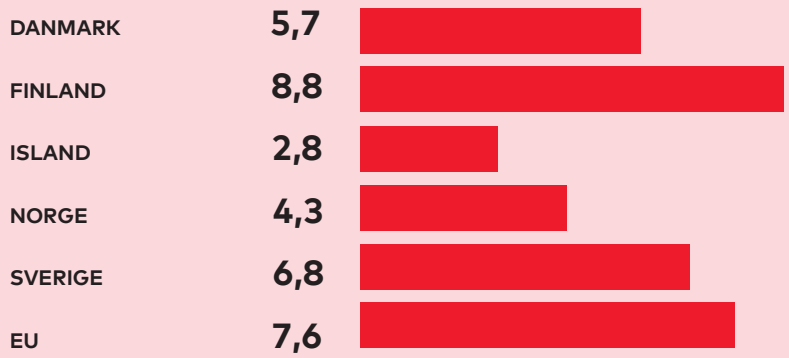



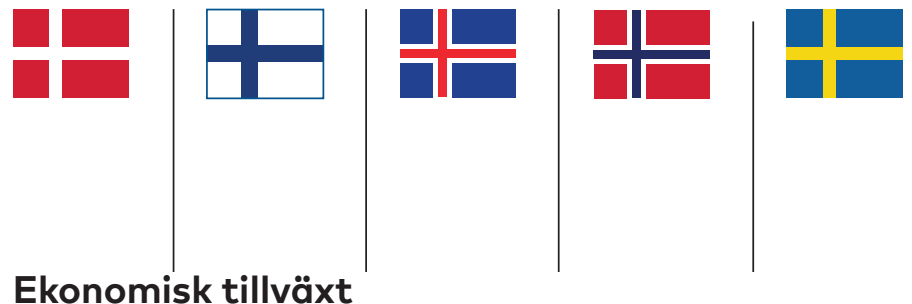

Ekonomisk tillväxt

Procent (2017)

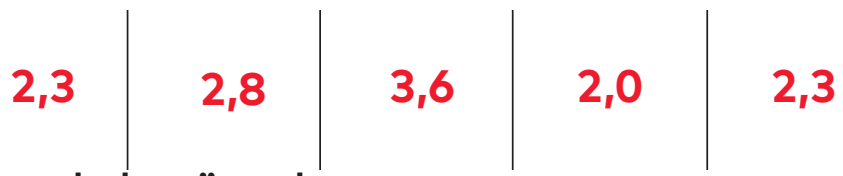

Bytesbalansöverskott

Procent av BNP (2017)

Ränta

$$
\begin{array}{l|l|l|l}
7,6 & 0,7 & 3,4 & 5,5
\end{array}
$$

Procent (2017)

$$
\begin{array}{l|l|l|l|l}
0,5 & 0,5 & 2,2 & 1,6 & 0,7
\end{array}
$$

Offentliga sektorns överskott

Procent av BNP (2017)

Inflation

$$
\begin{array}{l|l|l|l|l}
1,0 & -0,6 & 1,5 & 4,4 & 1,3
\end{array}
$$

Procent (2017)






\section{Total BNP}

Miljarder PPP, USD (2017)

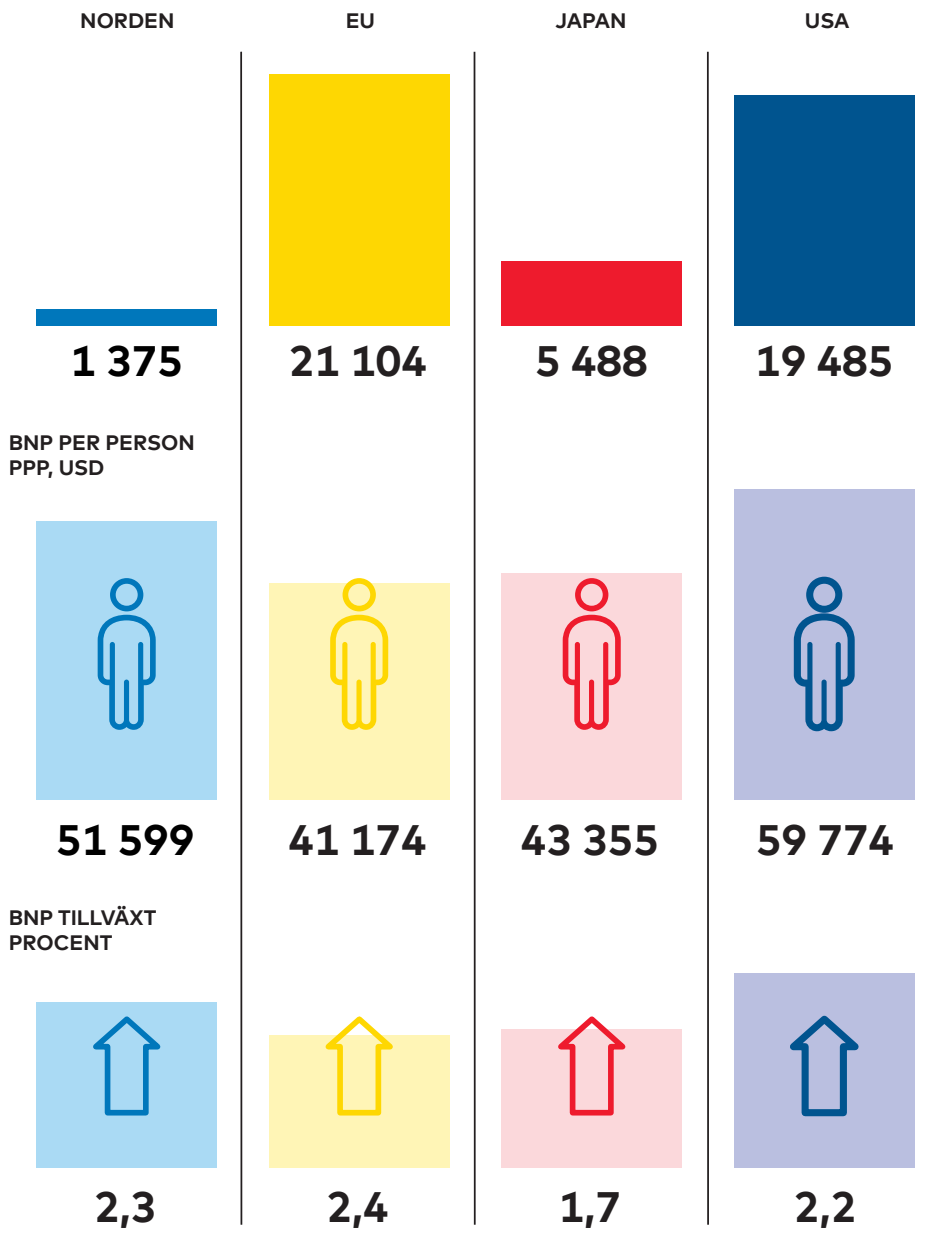




\section{Skatter}

Procent av BNP (2016)

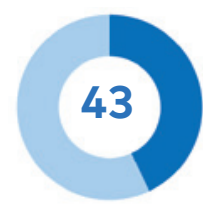

NORDEN
37

EU
31

JAPAN

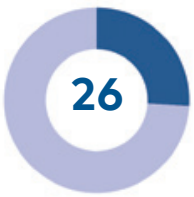

USA

\section{Export / import}

Miljarder USD (2017)

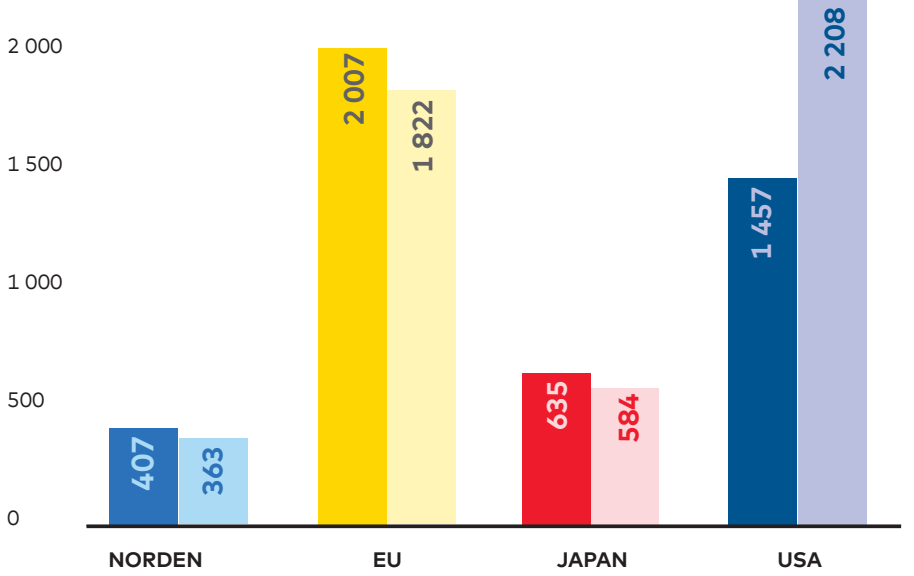




\section{Grönt Norden}

\section{Förnybar energi}

Procent av slutlig energiförbrukning (2016)

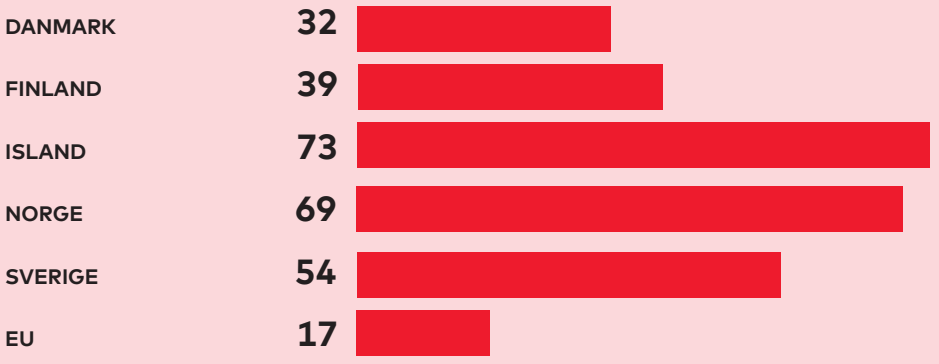



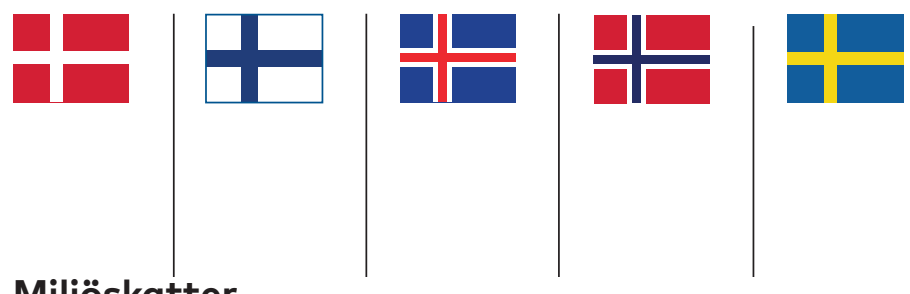

Miljöskatter

Procent av totala skatter (2016)

Energiintensitet

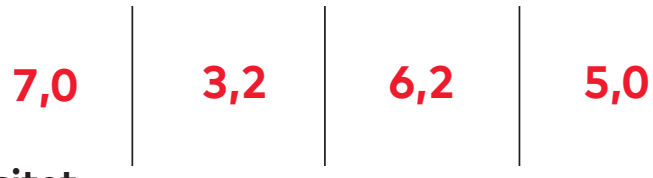

Terajoule per miljon BNP (2016)

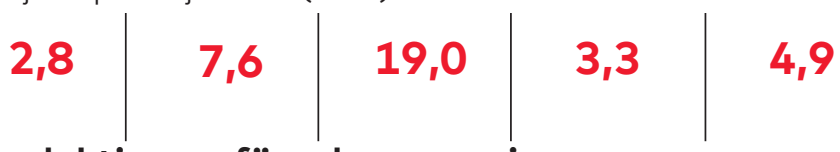

Produktion av förnybar energi

Procent av energiproduktionen (2016)

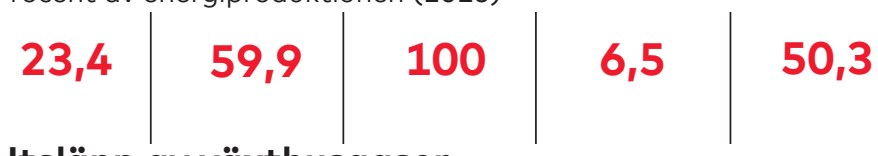

\section{Utsläpp av växthusgaser}

Ton per person (2015)

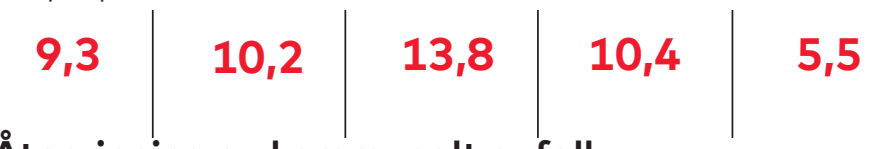

Återvinning av kommunalt avfall

Procent av avfall som återvinns (2016)

$$
\begin{array}{l|l|l|l|l}
28,6 & 29,2 & 25,5 & 28,0 & 32,6
\end{array}
$$




\section{Avlänkning mellan miljöbelastning och ekonomisk tillväxt i Norden \\ $2000=100$}



\section{Avlänkning mellan miljöbelastning och ekonomisk tillväxt i EU}

$2000=100$

130

BNP

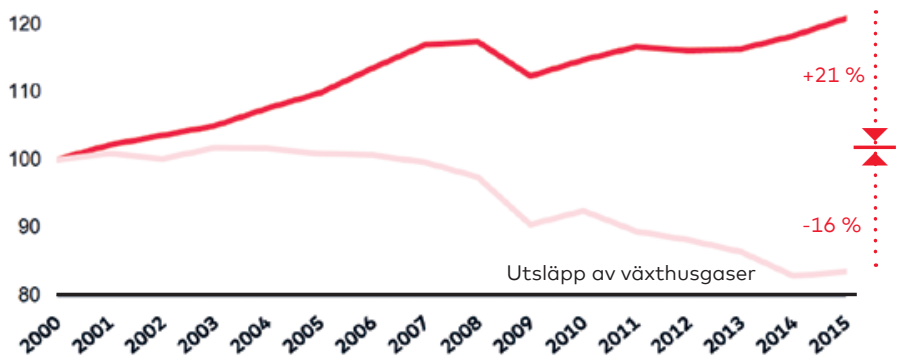




\section{Förnybar energiförbrukning}

(2015)

\section{DANMARK}

FINLAND

ISLAND

NORGE

SVERIGE

EU
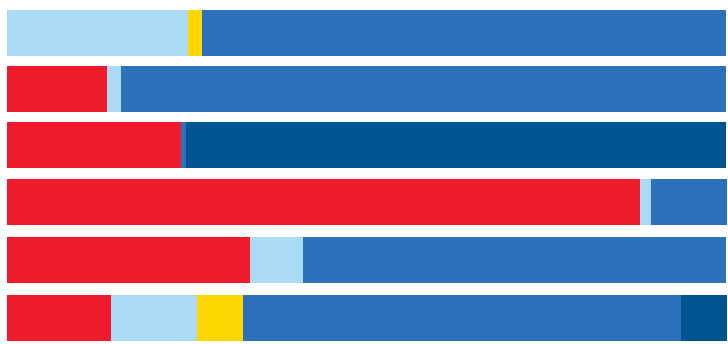

- Vattenkraft

Vindkraft

1. Solenergi

- Biomassa och förnybart avfall

- Geotermisk energi

\section{Inhemsk energiförbrukning}

(2015)

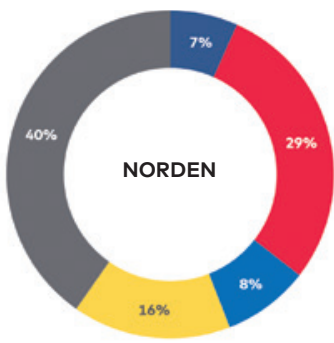

- Kol
- Olja Gas

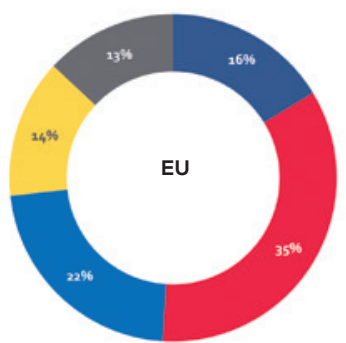

Kärnkraft

- Förnybara bränslen 


\section{Kön, näringsliv och arbete}

Styrelseledamöter i större börsnoterade bolag Kvinnor i procent (2017)

$\begin{array}{ll}\text { DANMARK } & 29 \\ \text { FINLAND } & 33 \\ \text { ISLAND } & 43 \\ \text { NORGE } & 43 \\ \text { SVERIGE } & 36 \\ \text { EU } & 25\end{array}$




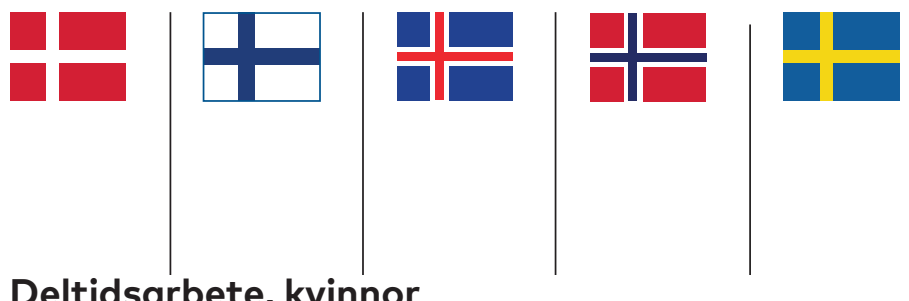

Procent av åldersgruppen 15-64 år (2017)

Deltidsarbete, män

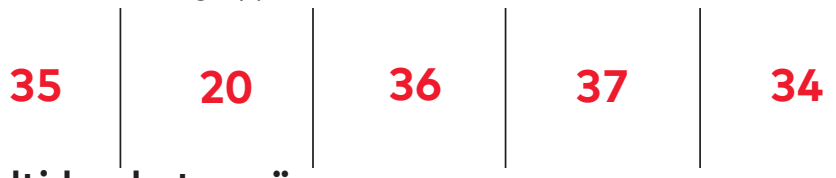

Procent av åldersgruppen 15-64 år (2017)



Arbetsgivare, kvinnor

Procent av personer i arbete som är arbetsgivare (2016)
1,8
1,9
2,1
0,9
1,6

Arbetsgivare, män

Procent av personer i arbete som är arbets!givare (21)16)
4,6
5,8
5,4
2,6
5,2

Kvinnor i de nationella parlamenten

Procent (2016)

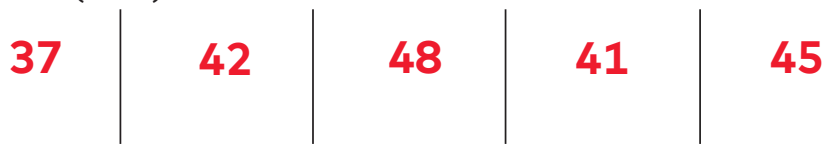

Kön, näringsliv och arbete 21 


\section{Sysselsättningsgrad}

Procent av åldersgruppen 15-64 år (2017)

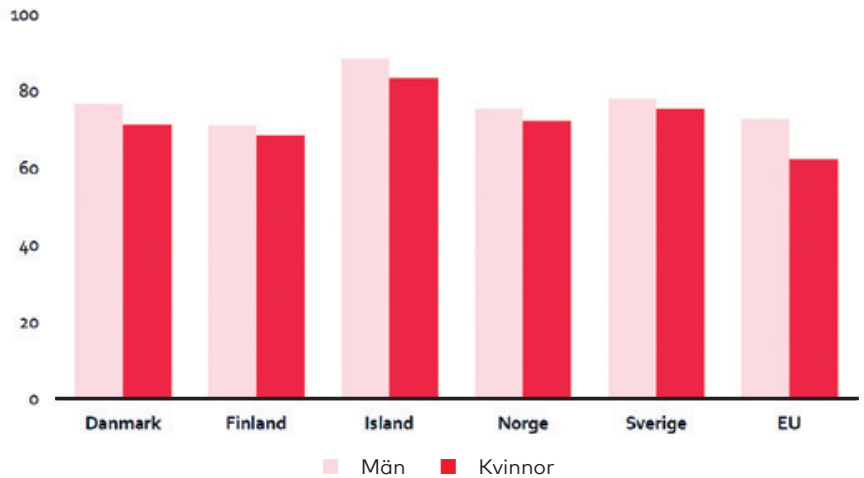

\section{Arbetslöshet}

Procent av åldersgruppen 15-64 år (2017)

10

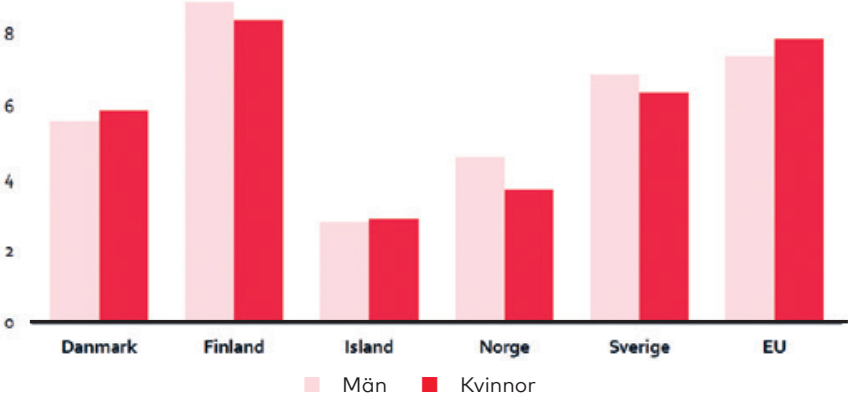

22 Kön, näringsliv och arbete 
Löneklyftan mellan könen

Procent (2016)

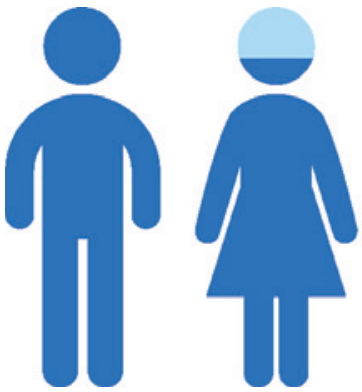

14,9

NORDEN

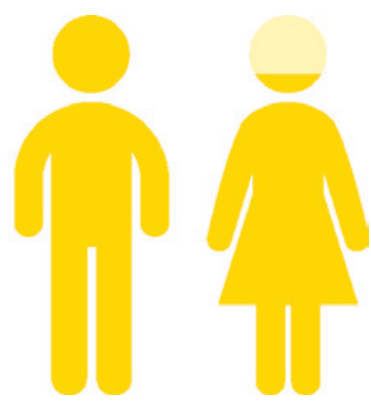

16,2

EU

Mäns andel av föräldraledigheten

Procent (2016)

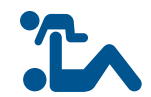

11

DANMARK
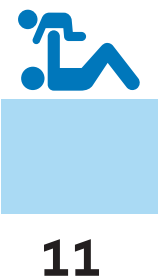

FINLAND
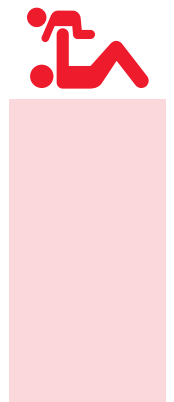

29

ISLAND
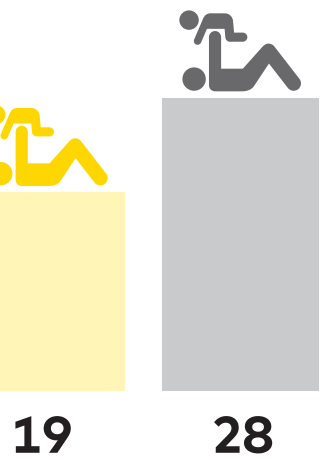

NORGE

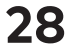

SVERIGE 


\section{Välfärd}

Mottagare av försörjningsstöd

Procent av befolkningen i åldern 18+ (2016)

DANMARK

2,4

FINLAND

3,5

1,0

ISLAND

1,7

NORGE

1,9

SVERIGE 


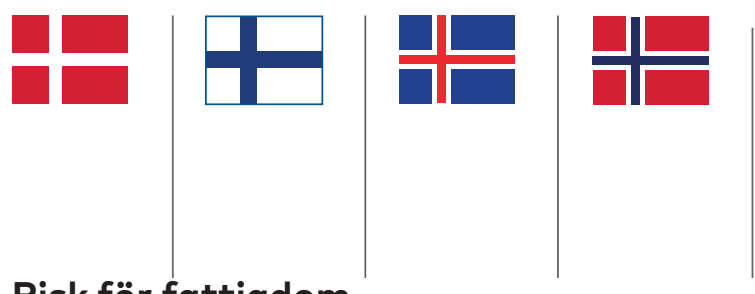

\section{Risk för fattigdom}

Procent av hushållen, ensamstående förälder med hemmavarande barn (2016)

$$
\begin{array}{l|l|l|l|l}
19,3 & 21,2 & 24,9 & 34,2 & 32,3
\end{array}
$$

Summerade fruksamhetstal

Antal barn per kvinna (2016)

$$
\begin{array}{l|l|l|l|l}
1,8 & 1,6 & 1,7 & 1,7 & 1,9
\end{array}
$$

Dödsfall som orsakats av cancer, kvinnor Per 100000 invånare (2015)
255
186
179
192
218

Dödsfall som orsakats av cancer, män Per 100000 invånare (2015)

\begin{tabular}{l|l|l|l|l}
288 & 241 & 206 & 223 & 239
\end{tabular}

Hälso- och sjukvårdskostnader

Procent av BNP (2016)

\begin{tabular}{l|l|l|l|l}
10,4 & 9,5 & 8,3 & 10,5 & 10,9
\end{tabular}


Summerade fruktsamhetstal

(2017)

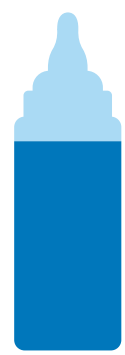

$$
1,8
$$

NORDEN

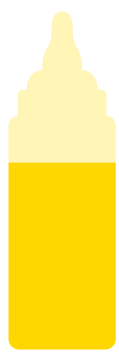

1,6

EU

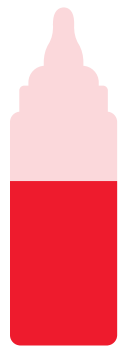

1,4

JAPAN

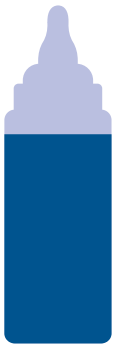

1,8

USA

\section{Medellivslängd}

Ålder (2016)

\section{Kvinnor}

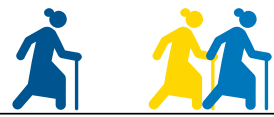

75

80

- USA 81,1 EU 83,6 NORDEN 83,9 - JAPAN 87,1

\section{5}

90

\section{Män}

75

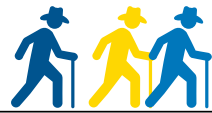

- USA 76,1

\section{0}

85

90

EU 78,2

- NORDEN 79,8

- JAPAN 81,0 


\section{Invandring till Norden}

(2016)

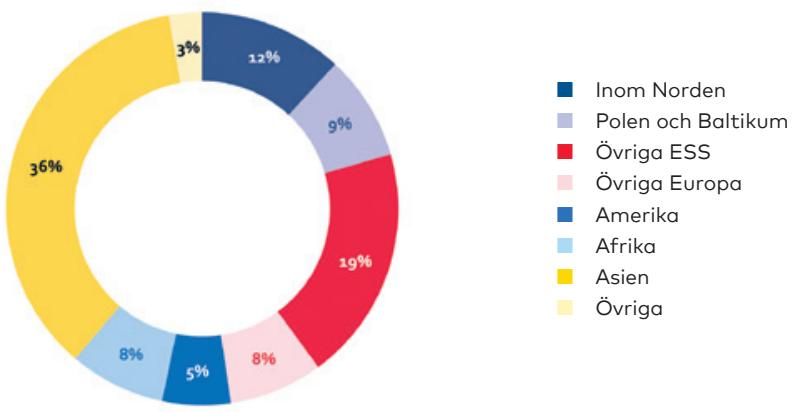

\section{Utvandring från Norden}

(2016)

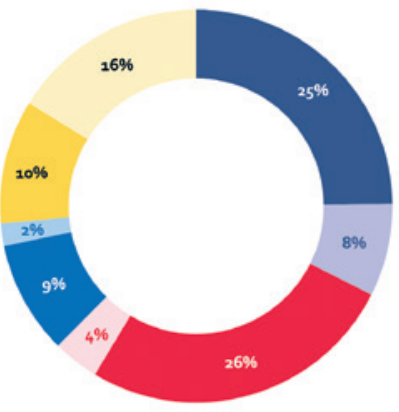

Inom Norden

- Polen och Baltikum

- Övriga ESS

Övriga Europa

- Amerika

Afrika

Asien

Övriga 


\section{Kultur och innovation}

Offentliga utgifter till kultur samt fritids- och sportverksamhet Procent av BNP (2016)

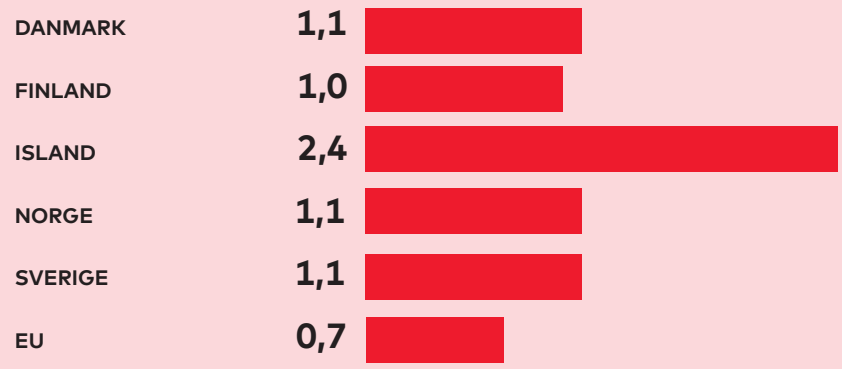




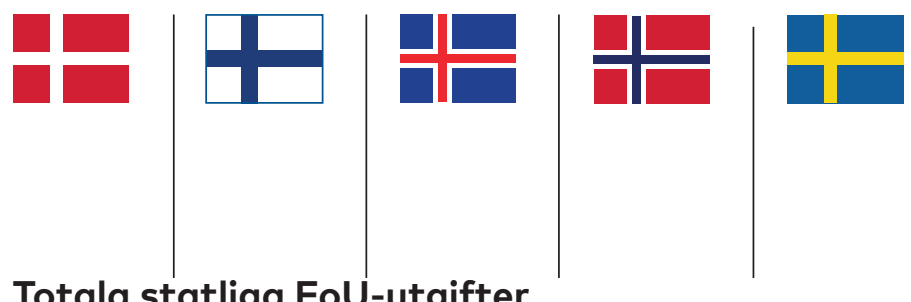

\section{Totala statliga FoU-utgifter}

Procent av BNP (2016)

\section{Beviljade patent}

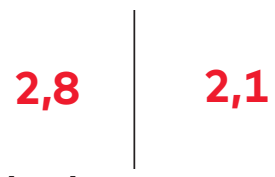

2,0

3,3

Per miljon invånare (2017)



Per miljon invånare (2016)

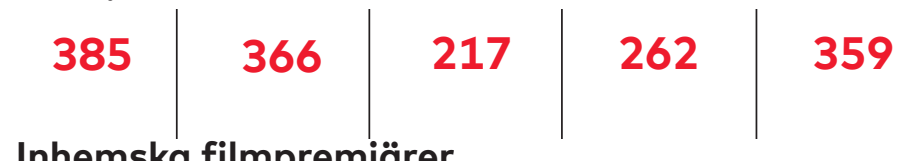

Inhemska filmpremiärer

Procent av alla filmpremiärer (2017 - Island 2014)

Museibesök

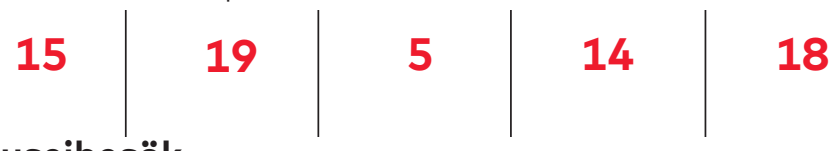

Antal besök per 100 invånare (2017 - Island och Sverige 2016)



Kultur och innovation 29 


\section{Inköp på nätet}

Procent av befolkningen (2017)

100

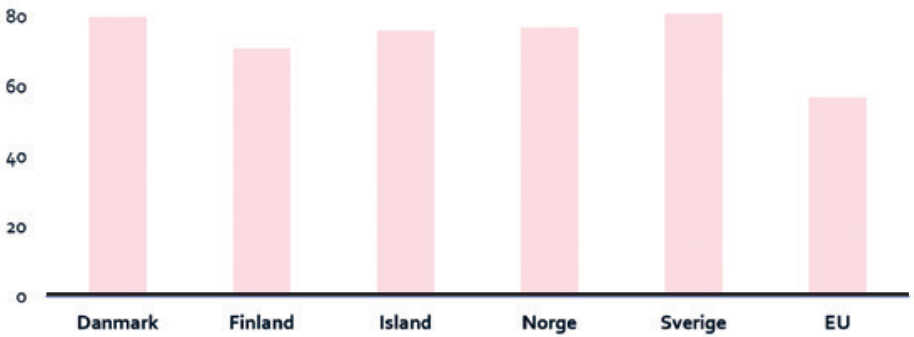

\section{Nya företag}

Index 2007=100






\section{Biografbesök}

Per invånare (2016)

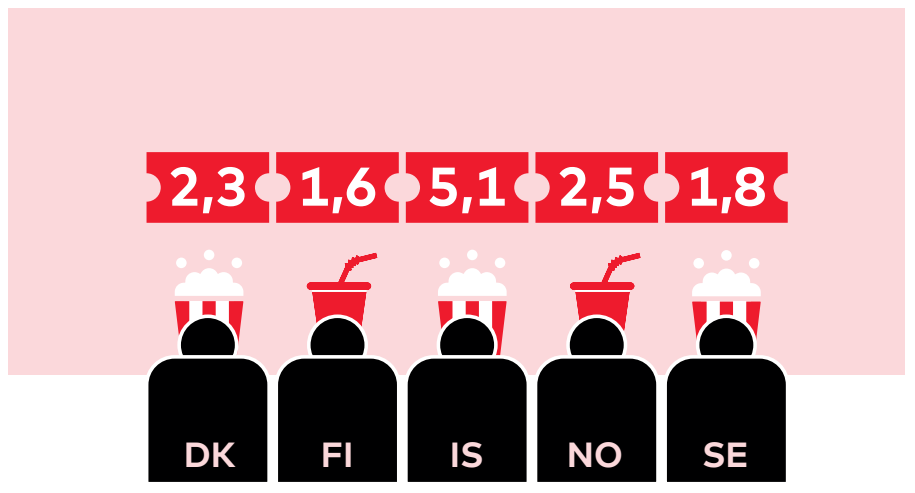

\section{Anställda inom kultursektorn}

Procent av den totala sysselsättningen (2016)

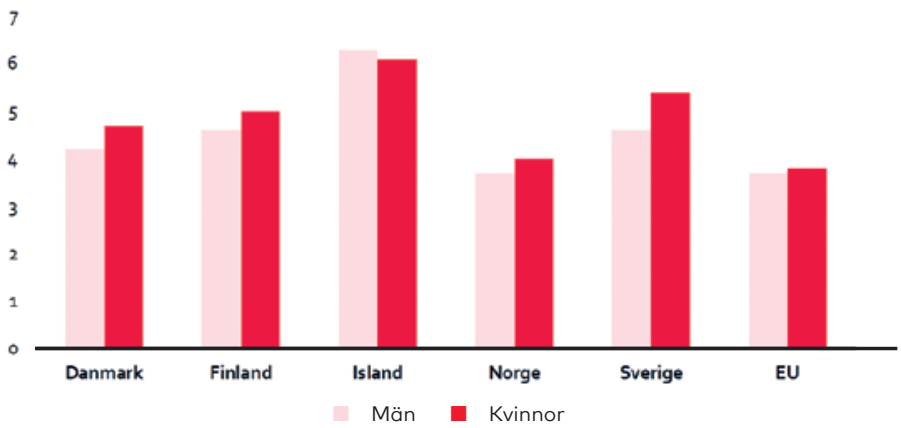




\section{Barn och unga}

Offentliga utgifter till utbildning

Procent av BNP (2016)

DANMARK

FINLAND

ISLAND

NORGE

SVERIGE

EU

$$
6,9
$$

6,1

7,1

5,6

6,6

4,7 

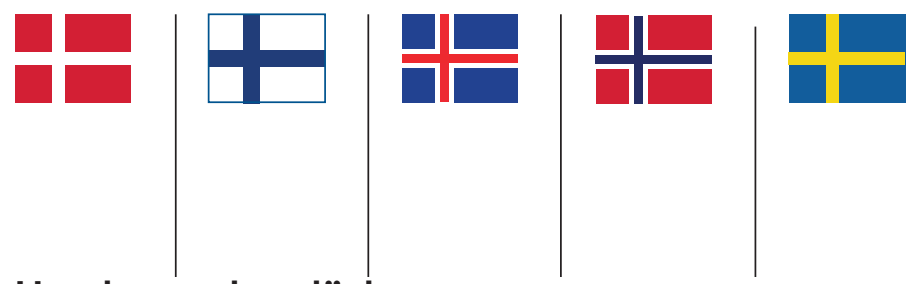

\section{Ungdomsarbetslöshet}

Procent av åldersgruppen 15-24 år (2017)

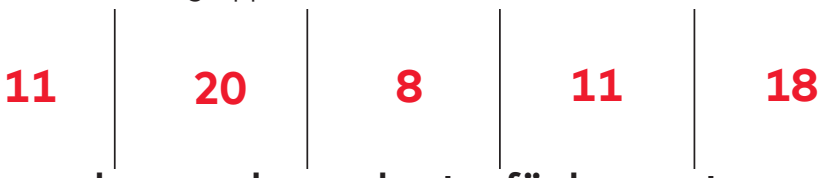

Barn och unga placerade utanför hemmet

Per 1000 i åldersgruppen 0-17 år (2015)
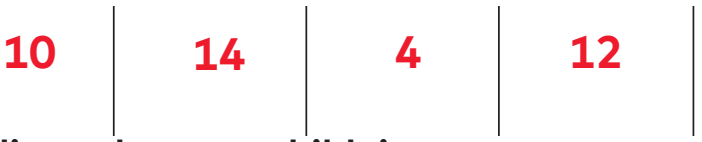

10

Tidigt avbruten utbildning

Procent i åldersgruppen 18-24 år (2016)

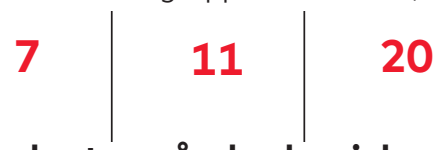

Studenter på akademiska utbildningar Procent av åldersgruppen 20-39 år (2015)

PISA
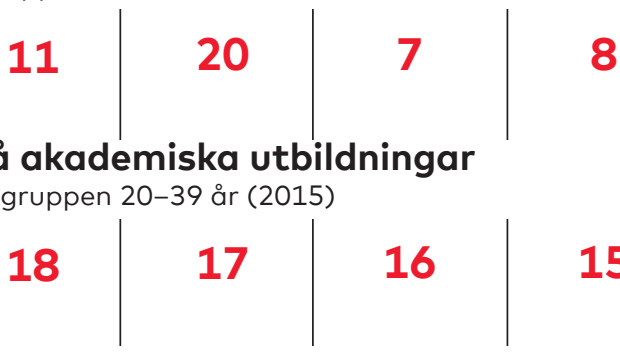

Elevernas prestation i naturvetenskaper (2015)

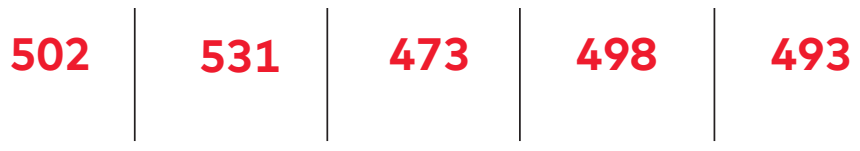




\section{Studenter utomlands}

Procent som studerar i ett annat nordiskt land (2015/2016)
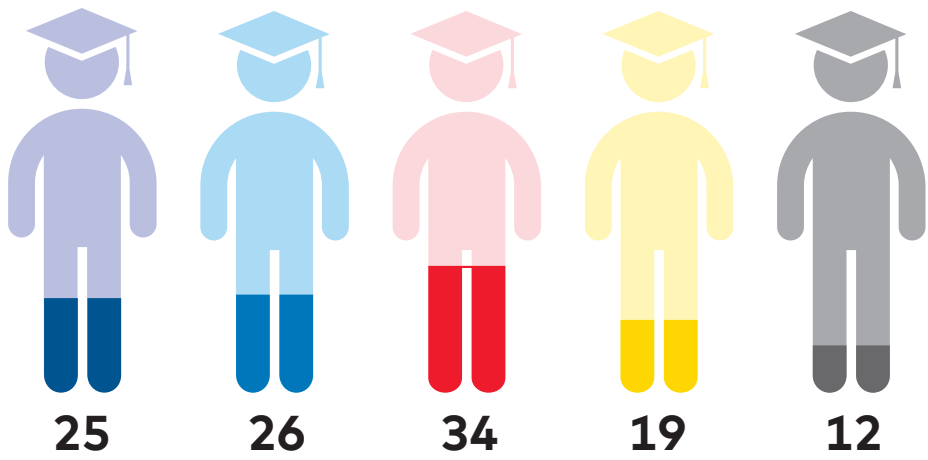

DANMARK

FINLAND



19

12

ISLAND

NORGE

SVERIGE

\section{Ekonomiskt stöd för studerande}

Euro i månaden (2017)

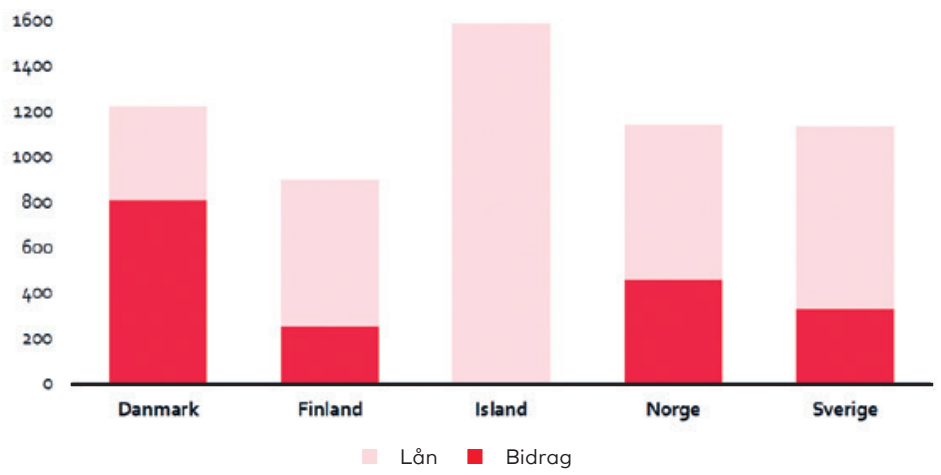




\section{Populäraste namnen bland nyfödda 2017}

DANMARK

GRÖNLAND

FÄRÖARNA

FINLAND

ÅLAND

ISLAND

NORGE

SVERIGE

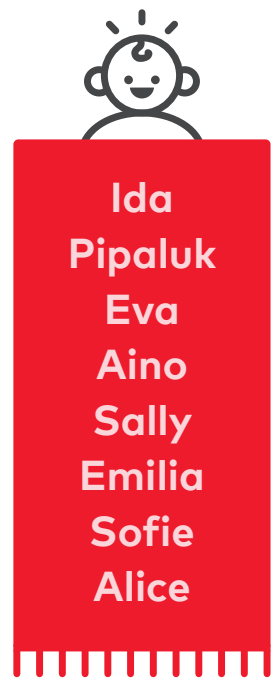


Nordiska ministerrådet

Nordens Hus

Ved Stranden 18

DK-1061 Köpenhamn K

www.norden.org

ANP 2018:818

ISBN 978-92-893-5823-1 (PRINT)

ISBN 978-92-893-5824-8 (PDF)

ISBN 978-92-893-5825-5 (EPUB) 